\title{
Prevalence of brucellosis and its outcome in Tertiary Care Hospital Makkah.
}

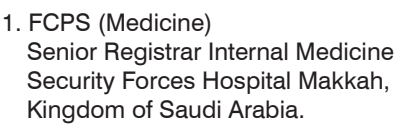

Correspondence Address: Dr. Imran Nazir

278- Jinnah Colony Faisalabad. Pakistan.

imrannazir40@gmail.com

Article received on: 01/06/2020 Accepted for publication: $12 / 08 / 2020$

\begin{abstract}
Imran Nazir ${ }^{1}$
ABSTRACT... Objectives: To see the prevalence and outcome of Human brucellosis in Makkah. Study Design: Cross Sectional study. Setting: Security Forces Hospital, Makkah. Period: August 2016 to August 2019. Material \& Methods: Patient's data was collected for the last 3 years. Simple randomized sampling technique was adopted and data was collected and analyzed using SPSS version 24. Univariate comparisons were done by using Chi square test. Results: This study enrolled 241 patients with predominant age group of 1540 years (41.9\%). Incidence rate in Makkah is 4.01 per 100,000 persons per year. Male were predominant $(67.2 \%)$. About fifty-seven (57.3) \% patients belonged to urban areas and the risk of acquisition of brucellosis was the consumption of unpasteurized milk in $138(57.3 \%)$ patients. Most common clinical presentation was fever (95.4\%) without a definite focus in 200 patients (83\%), Eighty-three (83\%) patients had uncomplicated brucellosis. The most common (67.2\%) treatment regimen was rifampicin and doxycycline for 6 weeks. Relapse rate was reported $10.8 \%$. Death rate was reported to be $0.9 \%$. Conclusion: Brucellosis still affects health of Saudi population and causes economic burden. It is recommended to keep up the efforts to decrease the brucellosis incidence rate toward zero.
\end{abstract}

Key words: $\quad$ Brucellosis, Prevalence, Clinical Features, Saudi Arabia.

Article Citation: Nazir I. Prevalence of brucellosis and its outcome in Tertiary Care Hospital Makkah. Professional Med J 2020; 27(12):2574-2580.

https://doi.org/10.29309/TPMJ/2020.27.12.5045

\section{INTODUCTION}

Human brucellosis is one of the major bacterial zoonosis reported worldwide. ${ }^{1}$ The causative organism is a gram-negative bacterium of Brucella genus, which is non-encapsulated non-spore forming coccobacilli. Globally more than 500,000 new cases per year are reported. Different geographical regions has various annual incidence, stands from $<2$ to $500 / 1,000,000$ population. ${ }^{2}$ Brucellosis still considered a major debilitating illness that leads to cause severe human morbidity. More prevalent areas of brucellosis are western parts of Asia, India, Middle Eastern, Southern European and Latin American countries. ${ }^{3,4}$

Saudi Arabia has infection rate of about 70 per 100,000 people. ${ }^{5}$ According to Ministry of Health 2018 Statistics book, incidence rate is gradually increasing again since 2014. The western part of kingdom of Saudi Arabia (KSA) has the least number of cases. Largest number of cases are seen in Al-Qassim as compared to Aseer in the south, Hail and Northern Borders in the north and the highest $\left(25^{\text {th }}\right)$ percentile of infection rate is seen in above areas. ${ }^{6}$

Ingestion of raw milk, cheese, meat; through direct contact with the infected animals, products of conception, animal discharges or through inhalation of infectious aerosols are major transmission vectors that can infect human. ${ }^{7}$

Diagnosis of human brucellosis is commonly difficult and challenging because of overlapping clinical presentation with many other bacterial infections. Main clinical symptom of brucellosis are undulant fever, night sweats, weight loss and arthralgia. Brucellosis is one of the causes of fever of prolonged duration in endemic areas and pyrexia of unknown origin (PUO)..$^{8,9}$ The key factor to control the spread of this disease is 
accurate and early diagnosis. Rose Bengal plate test (RBPT), complement fixation test, ELISA and serum agglutination test (SAT) are commonly used serological tests for the diagnosis of brucellosis. ${ }^{10,11,12}$ The genus-specific polymerase chain reaction (PCR) assay can be done to specify species of Brucella. ${ }^{13}$ But in Brucella endemic areas, the gold standard test is culture due to adequate sensitivity, ease of performance, dependability and lower cost. ${ }^{14,15}$ Brucellosis focal form or complication is assessed initially on clinical grounds by bone and joints, genitourinary, neurological, cardiac and pulmonary sign and symptoms. 'Relapse' was defined as the positive blood or body fluid culture following the completion of treatment along with reappearance of the symptoms. Usage of different antibiotic combinations depend upon multiple factors like blood culture/sensitivity, anatomical site of infection and drug side effects etc. ${ }^{16}$

Prevention is much easier, safer, has fewer side effects, and less cost compared to the treatment. When facing a zoonotic disease such as Brucellosis, controlling the vectors is very important for prevention. Preventive measures of brucellosis infection include consuming processed meat, pasteurizing milk, regular checkup of animals, and their vaccinations, also following health safety measure when dealing with infected animals, and during work in laboratories dealing with Brucella species. ${ }^{17,18,19}$ Brucellosis implies a significant public health impact in Saudi Arabia. So this study is panned to know the incidence rate, the trend of human brucellosis and its outcome in the Makkah region.

\section{MATERIAL \& METHODS}

This cross-sectional study was carried out at Security Forces Hospital, Makkah to see the prevalence and outcome of Human brucellosis in Makkah. All diagnosed brucellosis patients' data were collected for the last 3 years (August 2016 to August 2019) using simple random sampling technique. All Patients were included according to the inclusion criteria and then categorized into non-focal and focal disease groups according to the anatomical site of involvement. Inclusion criteria: (1). Agglutination test titre of at least
$1: 320$ in addition to the signs and symptoms was accepted as a case of brucellosis. (2). Isolation of Brucella species through a blood culture. (3). A four-fold rise in agglutination test titre over a period of four weeks. Pregnant patients were excluded from this study. All patients' demographic data, clinical symptoms and laboratory parameters were documented during the course of hospital stay followed by OPD basis. Data was represented as mean \pm SD values. SPSS version 24 was used for Statistical analysis. Univariate comparison was done by using Chi-square test.

\section{RESULTS}

Totally 241 cases of brucellosis were documented of which $162(67.2 \%)$ were male with a predominant (41.9\%) young age group (15-40 years). See details in Table-I. My study showed the Incidence rate of brucellosis 4.01 per 100,000 persons per year in Makkah. Age had a statistically significant association $(P<0.05)$ with raw milk and cheese intake.

Patients belonging to the rural areas were $42.7 \%$. Forty-six patients (19\%) had underlying comorbid conditions like type 2 diabetes mellitus and hypertension. Thirty-one patients (12.9\%) had a significant risk of acquisition of brucellosis with direct exposure to livestock. Unpasteurized milk usage was seen in $57.3 \%$ and $28.1 \%$ patients consumed local cheese. There is statistically significant association $(P<0.05)$ between usage of raw milk and cheese and the Titre of Brucella Melitensis and Abortus. Bacteremia was seen in $53.1 \%$ patients, osteoarticular involvement in $11.3 \%$ patients, while $4.6 \%$ patient had genital involvement and $1.2 \%$ patient had neurobrucellosis. Fever (95.4\%), myalgia (60.2\%) and weight loss (5.6\%) were the common symptoms and had association $(P<0.05)$ with diagnosis and outcome of brucellosis. Serological tests showed a significant titre of serum agglutination test $(\geq 1: 320)$ with titre as high as 1:1280 for both Brucella strains and only $2.9 \%$ patients showed agglutination titre $<1: 320$. All blood cultures showed confirmed brucellosis with Brucella melitensis that was susceptible to all drugs. Rifampicin (600 mg orally once daily) and doxycycline (100 mg twice a day) combination 
therapy for 6 weeks was used in 162 patients $(67.2 \%)$. Another regimen was used according to patients clinical, serological and drug tolerance status (see Table-II). Nineteen patients (7.8\%) were lost to follow-up and their treatment and outcome was not available. Patients with uncomplicated brucellosis were treated for a total duration of 6 weeks. Patients with neurobrucellosis were treated for 12-24 months and osteoarticular involvement was treated for 3 and 6 months, while genital brucellosis cases were treated for 3 months. Twenty-six patients (10.8\%) who were followed up had relapse mostly due to drug compliance or re-exposure. Two hundred fifteen patients (89.2\%) were improved while 5 patients (02\%) did not improve. Death was reported in 2 patients $(0.8 \%)$.

\begin{tabular}{|c|c|c|c|c|}
\hline Variables & Frequency & Mean & SD & Percentage \\
\hline $\begin{array}{l}\text { Age: } \\
<14 \text { yrs. } \\
15-40 \text { years } \\
41-60 \text { years } \\
>60 \text { years } \\
\text { Total }\end{array}$ & $\begin{array}{c}20 \\
101 \\
64 \\
56 \\
241\end{array}$ & 2.65 & 0.929 & \begin{tabular}{c|}
8.3 \\
41.9 \\
26.6 \\
23.2 \\
100
\end{tabular} \\
\hline $\begin{array}{l}\text { Gender: } \\
\text { Male } \\
\text { Female }\end{array}$ & $\begin{array}{c}162 \\
79\end{array}$ & 1.67 & 0.470 & $\begin{array}{l}67.2 \\
32.8\end{array}$ \\
\hline $\begin{array}{l}\text { Residence: } \\
\text { Rural } \\
\text { Urban }\end{array}$ & $\begin{array}{l}103 \\
138\end{array}$ & 1.43 & 0.496 & $\begin{array}{l}42.7 \\
57.3\end{array}$ \\
\hline $\begin{array}{l}\text { Region: } \\
\text { Makkah } \\
\text { Taif } \\
\text { Jeddah } \\
\text { Others }\end{array}$ & $\begin{array}{c}213 \\
11 \\
03 \\
14\end{array}$ & 1.49 & 1.761 & $\begin{array}{c}88.4 \\
4.6 \\
1.2 \\
5.8\end{array}$ \\
\hline $\begin{array}{l}\text { Occupation: } \\
\text { Police } \\
\text { Army } \\
\text { Student } \\
\text { House wife } \\
\text { Retired Govt. } \\
\text { No work }\end{array}$ & $\begin{array}{c}70 \\
27 \\
42 \\
61 \\
35 \\
6\end{array}$ & 1.67 & 1.465 & $\begin{array}{c}29 \\
11.2 \\
17.4 \\
25.3 \\
14.5 \\
02.5\end{array}$ \\
\hline $\mathrm{H} / \mathrm{O}$ contact e animals & 31 & 1.87 & 0.335 & 12.9 \\
\hline H/O Raw milk intake & 138 & 1.43 & 0.496 & 57.3 \\
\hline $\mathrm{H} / \mathrm{O}$ Local Cheese intake & 64 & 1.72 & 0.450 & 28.1 \\
\hline Family $\mathrm{H} / \mathrm{O}$ Brucellosis & 33 & 1.86 & 0.344 & 13.7 \\
\hline $\begin{array}{l}\text { H/O Co- morbidity: } \\
\text { DM+ HTN } \\
\text { No H/O } \\
\text { Others }\end{array}$ & $\begin{array}{c}46 \\
192 \\
03\end{array}$ & 2.06 & 0.722 & $\begin{array}{c}19 \\
79.7 \\
1.3\end{array}$ \\
\hline $\mathrm{H} / \mathrm{O}$ Fever & 230 & 1.05 & 0.209 & 95.4 \\
\hline H/O MSK Pain & 145 & 1.40 & 0.491 & 60.2 \\
\hline $\mathrm{H} / \mathrm{O}$ Wt. Loss & 13 & 1.94 & 0.230 & 5.6 \\
\hline
\end{tabular}




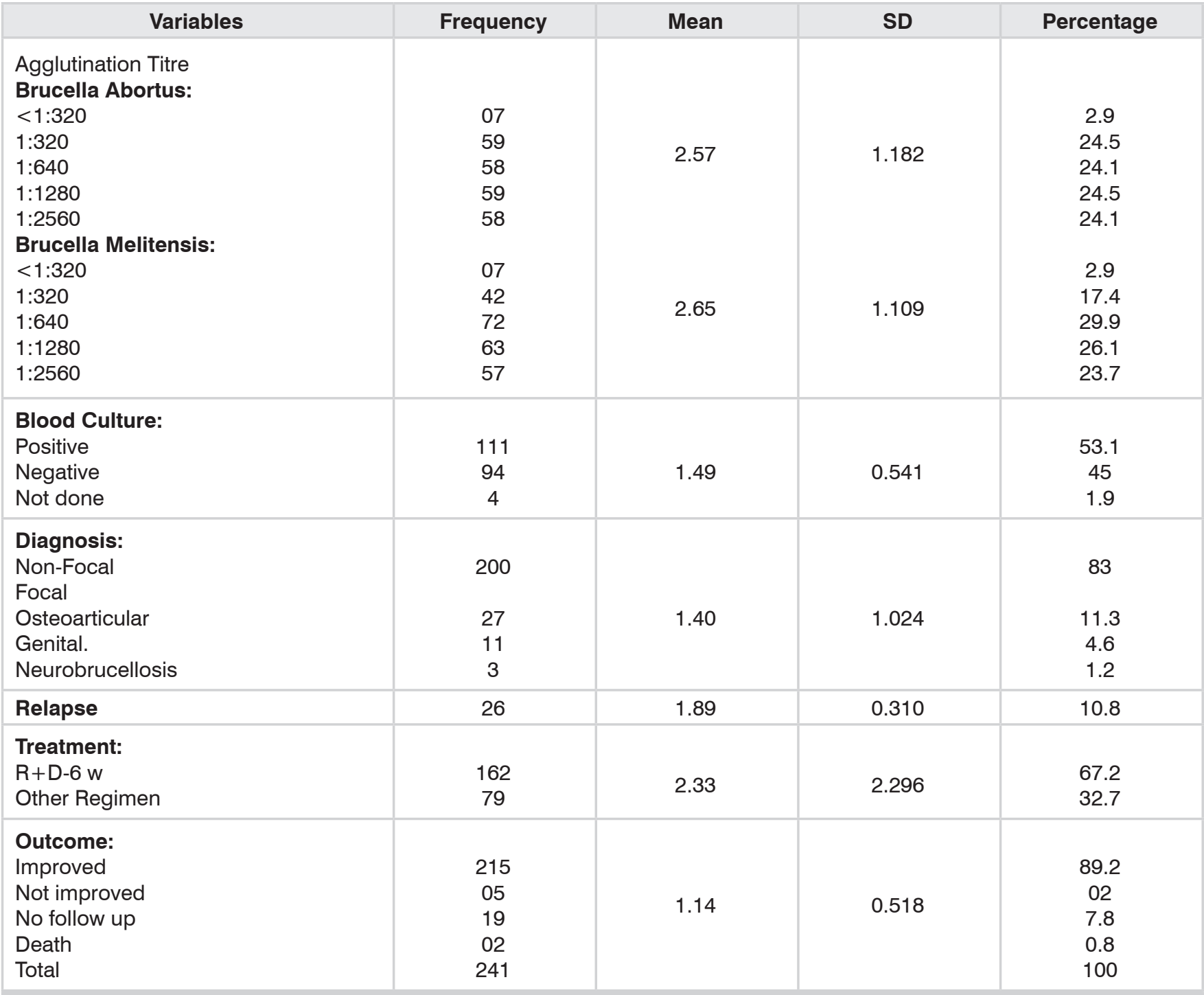

Table-II. Serological, treatment and outcome parameters of brucella patients

\section{DISCUSSION}

Brucellosis is a zoonotic infectious disease, also considered as one of the neglected diseases that as it does not have enough awareness like other infectious diseases. The incidence rate of brucellosis in Saudi society has an increasing trend (IR 10.1 in 2014 and IR: 16.3 in 2018). Globally developing regions still has a crucial health issues regarding human brucellosis. ${ }^{20}$

The highest number of cases are observed in Al-Qassim and Aseer region followed by Hail and the Northern borders of Saudi Arabia ${ }^{21} \mathrm{~A}$ low prevalence of brucellosis (2.6\%) is seen in Al-Medina region ${ }^{22}$, While highest prevalence of brucellosis (38.03\%) was documented in Hawtat Sudair city KSA. ${ }^{23}$ My study showed an incidence rate of 4.01 cases per 100,000 population per year in Makkah that is better than other endemic regions of KSA but still higher than Al-Medina region and most other developed countries..$^{20,24,25}$

The factors that effect on the prevalence are different geographically from region to region.so prevalence of brucellosis is not well documented according to different cities. Moreover, the modern lifestyle of Makkah also affects its prevalence. My study has a preponderance of males (67.2\%) with age group 15-40 years similar to previously global and local studies. ${ }^{16,26,27}$ 
High risk group people are of 15-40 years followed by 41-60 years old in my study, that is comparable with other studies high risk age group people in Saudi Arabia. ${ }^{28,29}$ These studies also revealed a lower incidence of brucellosis in younger aged group which is consistent with a study done in Kuwait. ${ }^{30}$ The most common symptoms documented in my study have fever, myalgia and wt. loss that are same as seen globally in previous literature review. ${ }^{27,28}$ Exposure to livestock and raw milk ingestion was important significant (12.9\% and $57.3 \%$ respectively) factors in my study that were consistent with previous reports. ${ }^{31}$

Co-morbidities rate was $19 \%$ in my study that were type 2 diabetes and hypertension. Over the past few years, several randomized controlled trials and systematic reviews on the treatment of human brucellosis (that included mostly adult patients) have been published. ${ }^{32,33}$ showed combination therapy (rifampicin and doxycycline) for 6 weeks in uncomplicated cases. This regimen was used in $67.2 \%$ patients in our study that had non focal brucellosis. Blood culture was positive in 53.1\% patients and Brucella melitensis was seen in cultures and was sensitive to all drugs in $100 \%$ cases. Brucella melitensis remains the principle cause of human brucellosis and less frequently Brucella abortus in Saudi Arabia. ${ }^{34}$ Relapse rate was found $10.8 \%$ in my study mostly due to non - compliance to treatment and re-exposure. Patient's improvement was $89.2 \%$ and death rate was observed $0.8 \%$ in my study. Early diagnosis, treatment and good compliance always gives a good outcome and less morality.

IR of brucellosis in Saudi Arabia is documented by region vise. That's why it is not possible to find actual city/area of infection. Limitation of our study is that it was single center study and all study population was Saudi and mostly were from government sector. Health authorities improved strategic plans on brucellosis for health education to high risk groups/ the community at large, livestock vaccination and farm hygiene improvement thereby can reduce the transmission to the human population.

\section{CONCLUSION}

Brucellosis has still significant impact on Saudi population's health and economics. Brucellosis is difficult to control in KSA because of high numbers of animals import yearly, behavior of rural area livestock owners towards awareness of the risks of disease prevention and its spread and their tradition to drink raw milk. So, it is recommended to streamline and keep up the efforts of concerned authorities to decrease the brucellosis incidence rate to zero.

Medical Research Committee of hospital approved this study. Confidentiality and anonymity of the subjects was maintained as rules/policy of hospital and no names were mentioned in the questionnaires.

\section{CONFLICTS OF INTEREST}

All the authors declared $t$ no conflict of interest regarding this manuscript.

Copyright $(12$ Aug, 2020.

\section{REFERANCES}

1. Patil DP, Ajantha GC, Shubhada C, Jain PA, Kalabhavi $A$, Shetty PC et all. Trend of human brucellosis over a decade at tertiary care centre in North Karnataka. Indian J Med Microbiol 2019 Feb 12; 34:427-32.

2. Pathak AD, Dubal ZB, Doijad S, Raorane A, Rodrigues $\mathrm{S}$, Naik R, et al. Human brucellosis among pyrexia of unknown origin cases and occupationally exposed individuals in Goa Region, India. Emerg Health Threats J 2014; 7: 23846.

3. Mantur BG, Amarnath SK. Brucellosis in India - A review. J Biosci 2008; 33:539-47.

4. Mantur BG, Biradar MS, Bidri RC, Mulimani MS, Veerappa, Kariholu $P$, et al. Protean clinical manifestations and diagnostic challenges of human brucellosis in adults: 16 years' experience in an endemic area. J Med Microbiol 2006; 55:897-903.

5. Bakheet HG, Alnakhli HA. Brucellosis in Saudi Arabia: review of literature and epidemiology. J Trop Dis. 2019;7(304):2. doi:10.4172/2329-891X.1000304.

6. Abdulaziz D. Aloufi, Ziad A. Memish, Abdullah M. Assiri. Trends of reported human cases of brucellosis, Kingdom of Saudi Arabia, 2004-2012: Journal of Epidemiology and Global Health 2016; 6:1118. 
7. Wu G, Yang C, Li J, Liu N, Yao W, Zhang R, et al. Prevalence study of brucellosis among high risk people in Xinjiang region, China. Microbiology Discovery 2013; 1:2 Available from: http://dx.doi. org/10.7243/2052-6180-1-2.

8. Ciftçi E, Ince E, Dogru U. Pyrexia of unknown origin in children: A review of $\mathbf{1 0 2}$ patients from Turkey. Ann Trop Paediatr 2003; 23:259-63.

9. Baba MM, Sarkindared SE, Brisibe F. Serological evidence of brucellosis among predisposed patients with pyrexia of unknown origin in the north eastern Nigeria. Cent Eur J Public Health 2001; 9:158-61.

10. Rubio M, Barrio B, Díaz R. Usefulness of Rose Bengal, Coombs and counter-immunoelectrophoresis for the diagnosis of human brucellosis cases with negative seroagglutination. Enferm Infecc Microbiol Clin 2001; 19:406-7.

11. Mantur B, Parande A, Amarnath S, Patil G, Walvekar R, Desai $A$, et al. ELISA versus conventional methods of diagnosing endemic brucellosis. Am J Trop Med Hyg 2010; 83:314-8.

12. Islam MA, Khatun MM, Werre SR, Sriranganathan $\mathrm{N}$, Boyle SM. A review of Brucella seroprevalence among humans and animals in Bangladesh with special emphasis on epidemiology, risk factors and control opportunities. Vet Microbiol 2013; 166:317-26.

13. Al Dahouk S, Nöckler K. Implications of laboratory diagnosis on brucellosis therapy. Expert Rev Anti Infect Ther 2011; 9:833-45.

14. Godfroid J, Cloeckaert A, Liautard JP, Kohler S, Fretin $\mathrm{D}$, Walravens $\mathrm{K}$, et al. From the discovery of the Malta fever's agent to the discovery of a marine mammal reservoir, brucellosis has continuously been a reemerging zoonosis. Vet Res 2005; 36:313-26.

15. Elfaki MG, Al-Hokail AA, Nakeeb SM, Al-Rabiah FA. Evaluation of culture, tube agglutination, and PCR methods for the diagnosis of brucellosis in humans. Med Sci Monit 2005; 11:MT69-74.

16. Mani SS, Gunasekaran K, lyyadurai R, Prakash JA, Veeraraghavan B, Mishra AK, Sabnis K, Victor PJ, Martin S, Chandiraseharan VK, Hansdak SG, Varghese GM. Clinical spectrum, susceptibility profile, treatment and outcome of culture-confirmed brucellosis from South India. Indian J Med Microbiol 2018; 36:289-92.

17. Srivastava A, Chaudhary HS. Brucellosis: Its Diagnosis, Prevention and Treatment. J. Chem. $2011 ; 3(6): 912-7$.
18. Alavi SM, Motlagh ME. A review of epidemiology, diagnosis and management of brucellosis for general physicians working in the Iranian health network. Jundishapur J. Microbiol. 2012;5(2):384-7.

19. Baron S. Alphaviruses (Togaviridae) and Flaviviruses (Flaviviridae)--Medical Microbiology. University of Texas Medical Branch at Galveston; 1996.

20. Bakheet HG, Alnakhli HA. Brucellosis in Saudi Arabia: review of literature and epidemiology. J Trop Dis. 2019;7(304):2. doi: 10.4172/2329-891X.1000304.

21. Alshaalan MA, Alalola SA, Almuneef MA, Albanyan EA, Balkhy $\mathrm{HH}$, AIShahrani DA, AlJohani S. Brucellosis in children: Prevention, diagnosis and management guidelines for general pediatricians endorsed by the Saudi Pediatric Infectious Diseases Society (SPIDS) Int J Pediatrics Adolescent Med. 2014;1(1):40-46.

22. Al-Sekait MA. Epidemiology of brucellosis in $\mathbf{A l}$ medina region, Saudi Arabia. J Fam Community Med. 2000; 7 (1):47-53.

23. Alaidarous M. Prevalence of brucellosis in Hawtat Sudair City, Riyadh Province, Saudi Arabia. Majmaah J Health Sci. 2018; 1: 17-25.

24. Grunow R, Jacob D, Klee S, Schlembach D, JackowskiDohrmann S, Loenning-Baucke V, et al. Brucellosis in a refugee who migrated from Syria to Germany and lessons learnt, 2016. Euro Surveill. 2016:21.

25. Norman FF, Monge-Maillo B, Chamorro-Tojeiro S, Pérez-Molina JA, López-Vélez R. Imported brucellosis: A case series and literature review. Travel Med Infect Dis. 2016; 14:182-199.

26. Alkahtani AM, Assiry MM, Chandramoorthy HC, AlHakami AM and Hamid ME: Sero-prevalence and risk factors of brucellosis among suspected febrile patients attending a referral hospital in southern Saudi Arabia (2014-2018). BMC Infect Dis. 2020; 20 : 26. doi: 10.1186/s12879-020-4763-z.

27. Buzgan T, Karahocagil MK, Irmak H, Baran Al, Karsen $H$, Evirgen $O$, et al. Clinical manifestations and complications in 1028 cases of brucellosis: A retrospective evaluation and review of the literature. Int J Infect Dis 2010; 14: e469-78.

28. Aloufi AD, Memish ZA, Assiri AM, McNabb SJ. Trends of reported human cases of brucellosis, Kingdom of Saudi Arabia, 2004-2012. J Epidemiol Global Health. 2016; 6 (1):11-18.

29. Asaad AM, Alqahtani JM. Serological and molecular diagnosis of human brucellosis in Najran, southwestern Saudi Arabia. J Infect Public Health. 2012; 5 (2):189-194. 
30. Lulu AR, Araj GF, Khateeb MI, Mustafa MY, Yusuf AR, Fenech FF. Human brucellosis in Kuwait: A prospective study of 400 cases. Q J Med. 1988; 66 (249):39-54.

31. Memish Z, Mah MW, Al Mahmoud S, Al Shaalan M, Khan MY. Brucella bacteraemia: Clinical and laboratory observations in 160 patients. J Infect 2000; 40: 59-63.

32. Yousefi-Nooraie R, Mortaz-Hejri S, Mehrani M, Sadeghipour P. Antibiotics for treating human brucellosis. Cochrane Database Syst Rev. 2012; 10 : CD007179.
33. Solís García del Pozo J, Solera J. Systematic review and meta-analysis of randomized clinical trials in the treatment of human brucellosis. PLoS One. 2012; 7: e 32090.

34. Jokhdar HA. Brucellosis in Saudi rabia: Review of Literature and an Alarming Case Report in a Hospital in Jeddah. Med. J. Cairo Univ. 2009; 77, (3): 47-55.

\section{AUTHORSHIP AND CONTRIBUTION DECLARATION}

\begin{tabular}{|c|c|c|c|}
\hline Sr. \# & Author(s) Full Name & Contribution to the paper & Author(s) Signature \\
\hline 1 & Imran Nazir Ahmad & 1st Author
\end{tabular}

